\title{
Supinated forearm is correlated with the onset of medial epicondylitis in professional slalom water- skiers
}

\author{
Donato Rosa \\ Sigismondo Luca Di Donato \\ Giovanni Balato \\ Alessio D'Addona \\ Fabrizio Schonauer
}

Department of Public Health, Federico II University of Naples, Naples, Italy

Corresponding author:

Giovanni Balato

Department of Public Health, Federico II University of Naples, Naples, Italy

Via Sergio Pansini, 5

80131 Naples, Italy

E-mail: giovannibalato@gmail.com

\section{Summary}

Background: prolonged and laborious activities involving wrists and forearms has been long associated with the onset of epicondylitis. Slalom water-skiing can be included in this category. The purpose of the study is to analyse the correlation between the pronated or supinated position of forearms during water-skiing practice and the presence respectively of lateral and medial epicondylitis.

Methods: sixty-six pro and semi-pro slalom waterskiers were enrolled in the study. A questionnaire was submitted to each athlete. Diagnosis of lateral or medial epicondylitis was made through anamnesis and clinical exam by an expert orthopaedic surgeon. Chi-squared were performed for categorical variables, and Mann-Whitney $U$ test for continuous ones.

Results: from 116 upper limbs examined, we observed $15(12.9 \%)$ cases of lateral epicondylitis, $30(25.9 \%)$ cases of medial epicondylitis, 10 (8.6\%) were affected by both lateral and medial epicondylitis. Lateral and medial epicondylitis were associated $(95 \%$ C.I. $=2,489-26,355 ; P=<0,001)$ and the supinated position was correlated with medial epicondylitis (95\% C.I. $=1,529-9,542 ; P=0.003)$.

Conclusion: slalom water-skiing can be considered a high-risk sport for epicondylitis. In slalom water-skiers there is a correlation between devel- opment of lateral and medial epicondylitis in the same upper limb. Supinated position of forearms is strongly associated with the diagnosis of medial epicondylitis.

KEY WORDS: biomechanics, elbow, pain, tendinopathy, water-skiing.

\section{Introduction}

Medial and lateral epicondylitis are two types of tendinopathies involving the proximal insertion of the epitrochlearis muscles. Currently, the term "epicondylitis" is no longer used to describe an inflammatory state, but mostly structural changes in according to a degenerative pathway ${ }^{1-4}$. Epicondylitis causes radiating pain from the elbow to the wrist, with consequent loss of strength and functionality of the arm. Epicondylitis is more common in the dominant elbow $^{5-7}$. The prevalence of epicondylitis is between 1 and $3 \%$ in the general population ${ }^{8}$, in particular lateral epicondylitis ranges from 0.7 to $4 \%$, medial epicondylitis between 0.3 and $1.1 \%{ }^{9}$. Some studies showed a slightly higher prevalence of epicondylitis in women ${ }^{10}$. A constitutional risk factor for medial epicondylitis is obesity ${ }^{11}$. Repetitive, prolonged and laborious activities involving wrist and forearm movements has long been associated with the onset of epicondylitis ${ }^{12,13}$. Even activities that require grip strength can be considered at risk ${ }^{14}$. The functional deficits affect the overall quality of life the patients by limiting their ability to carry out routine activities, including their ability to work, resulting in an economic waste in terms of productivity and health-care costs ${ }^{7}$. Besides being associated with strenuous and repetitive work, epicondylitis has also been associated with some types of sports, in particular, lateral epicondylitis is generally associated with tennis, known as "tennis elbow", while medial epicondylitis with golf, known as "golfer's elbow". In tennis, a "bad" backhand shot is considered a risk factor for lateral epicondylitis ${ }^{15,16}$. In the golf swing, pronator teres muscle activity differs significantly between professional and amateur golfers ${ }^{17}$, which is probably one of the reasons of high prevalence of elbow injuries among amateurs ${ }^{18}$. Water-skiing, in particular slalom water-skiing, clearly shows some typical risk factors of epicondylitis ${ }^{12-}$ $14,19,20$. Slalom water-skiing is a surface water sport in which an individual is pulled behind a boat gliding on 


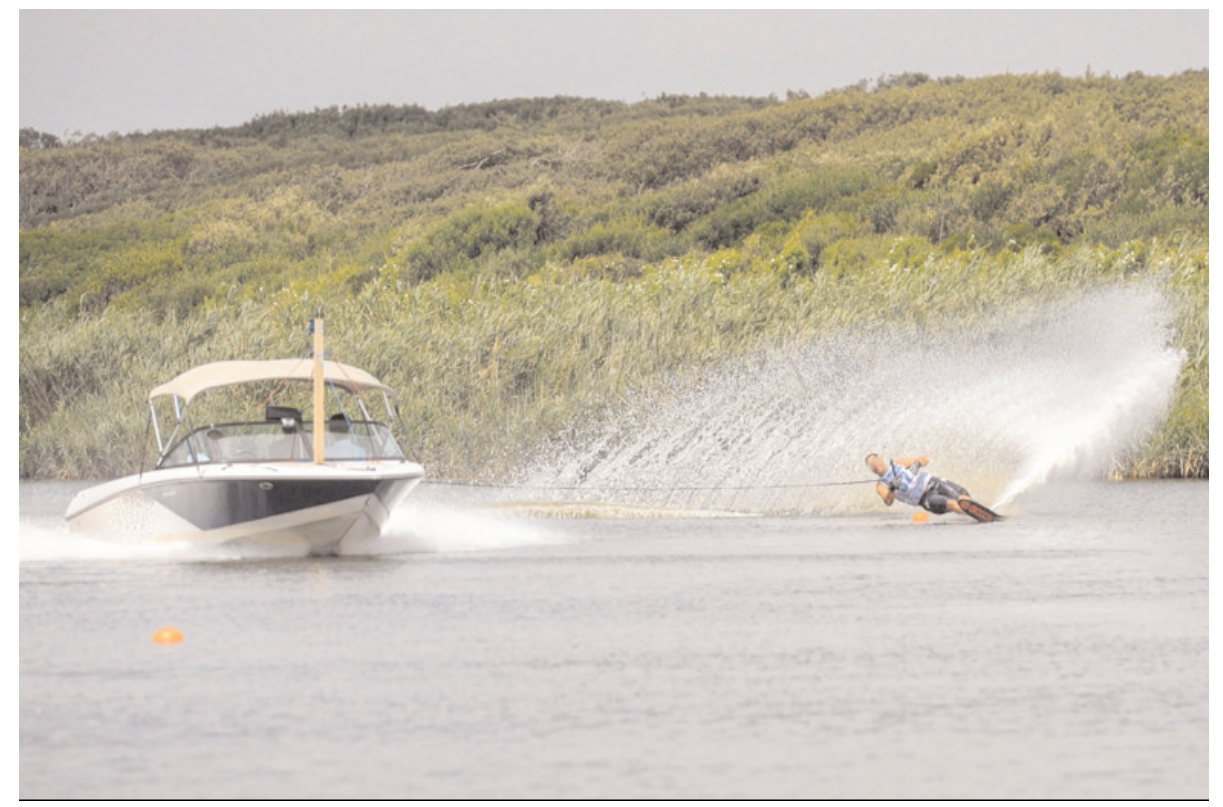

Figure 1. A slalom water-skiers during practice.

one ski (Fig. 1) with a forced position of the forearms during the practice; precisely one forearm is placed in pronated position while the other one is supinated. Slalom water-skiers put one foot in front of the other on the mono-ski, generally the dominant one. Athletes pass through a slalom course made of six buoys that the skier must go around in order to complete their performance. The turn buoys are positioned 11.5 metres away from the center of the slalom course. Every consecutive pass is more difficult than the one before it. When a pass is completed, the boat is sped up by 3 kilometres per hour ( $2 \mathrm{mph}$ ) up to the maximum speed for the division, based on gender and age ( 55 kilometres per hour for women and 58 kilometres per hour for men). After the skier has run their maximum speed pass, the rope is progressively shortened to make it more difficult. After rounding a turn buoy they start accelerating, and so their top speed will generally be more than double the boat's speed (pro-athletes can reach speeds above 116 kilometres per hour) and, at the hardest passes, the skiers undergo an extreme upper body torque ${ }^{19}$. The conventional way to grip the handle is the so called "baseball-bat grip": left-foot-forward skiers should hold the handle with their left palm down and right palm up, vice versa for right-foot-forward skiers. This position is used by almost all pro water-skiers because it puts athletes in a more balanced position, however it is not a mandatory rule. It is important to highlight that the baseball-bat grip influences the position of both forearms of the skier: one forearm is forced to assume a pronated position, the other is forced to assume a supinated position.

The purpose of our study is to analyse the correlation between the forced pronated or supinated position that the forearms of pro slalom water-skiers assume during practice, and the presence of epicondylitis.

\section{Materials and methods}

Our study involved 66 pro and semi-pro slalom water skiers with an average age of 35 years, ranged between 14 and $60($ IQR $=19)$, who practice water-skiing at least 3 hours a week on average. The research was conducted in accordance with the Declaration of Helsinki and the national and institutional ethical research standards. The informed consent of all patients was obtained before the registration of data and approved by the Local Ethics Committee. The study meets the ethical standards of the Journal ${ }^{20}$.

The exclusion criteria that we have applied for the study are:

- any limitation in the range of motion (ROM) of elbow and wrist;

- history of inflammatory arthritis involved in particular elbow and wrist;

- structural abnormality of the elbow and wrist;

- diagnosed peripheral nerve injury or motor deficit of upper limb;

- diagnosed cervical or upper extremity pathologies (e.g., cervical radiculopathy, whiplash injury, carpal tunnel syndrome);

- any musculoskeletal medical condition related to neck and upper extremity or diffuse pain syndrome (e.g., rheumatoid, fibromyalgia);

- any recent upper extremity trauma or fracture of upper limb with residual deformity;

- history of elbow or wrist surgery;

- osteoarthritis affecting the wrist or elbow;

- practice of other sports at risk (e.g. tennis, golf, others racket sports) at least 2 hour in a week on average;

- occupational criteria:

- work demanding high handgrip forces at least 1 hour per day; 
- repetitive movements of the hands or wrists at least 2 hours a day;

- specific job (e.g., typewriting, cash register work, computer display work, cooking) with duration of at least 4 hours per day;

- work with a vibrating tool.

A specific questionnaire was submitted to each athlete regarding:

- age;

- gender;

- number of years water-skiing and hours per week of slalom water-skiing on average;

- dominant upper limb (left or right);

- which upper limb (left/right) placed in pronation and which in supination (right/left) during sport practice;

- comorbidity;

- recent and remote detailed anamnesis for nervous and musculoskeletal system;

- practice of other sports (hours of practice per week in average);

- occupational information (according to exclusion criteria);

- pain in the lateral epicondyle region in the last two weeks (upper limbs, right and left);

- pain in the medial epicondyle region in the last two weeks (upper limbs, right and left).

A clinical examination was performed by an expert orthopaedics surgeon on both upper limbs, in order to evaluate:

- presence of structural abnormality and articular ROM of wrist and elbow;

- weight and height;

- ligamentous laxity;

- tenderness at the lateral humeral epicondyle;

- pain at the lateral humeral epicondyle region on resisted extension of the wrist with the elbow extended;

- tenderness at the medial humeral epicondyle;

- pain at the medial humeral epicondyle on resisted flexion of the wrist with the elbow extended.

Lateral and medial epicondylitis was diagnosed by the presence of at least two of the following criteria:

- pain in lateral or medial epicondyle region in the last two weeks;

- tenderness at the lateral or medial humeral epicondyle;

- pain at the lateral or medial humeral epicondyle region on resisted extension or flexion of the wrist with the elbow extended.

\section{Statistical analysis}

We performed an univariate analysis between lateral epicondylitis, as dependent variable, and 7 independent variables: age, gender, years of sport's practice, BMI, concomitant diagnosis of medial epicondylitis, hand dominance and pronated or supinated position of arms during practice. Next we performed an univariate analysis between medial epicondylitis and the same independent variables, but this time consider- ing the concomitant diagnosis of lateral epicondylitis. To establish whether these correlations were significant an age and gender adjusted multivariate analysis was performed. All independent variables that showed a significant $p$-value at univariate analysis were included in multivariate analysis. At descriptive statistic, quantitative variables were presented as median, range and interquartile range (IQR); qualitative variables were presented as number and percentage. We chose to analyse continuous variables with non-parametric tests because of the narrowness of the sample and the absence of a normal distribution of dataset established by Kolmogorov-Smirnov and Shapiro-Wilk tests. Statistical significance at univariate analysis was assessed by a chi-squared or Fisher's Exact Test (when values were $<5$ ) for categorical variables, and by a Mann-Whitney $U$ test for continuous variables. Multivariate analyses were performed through an age and gender adjusted logistic regression. Multicollinearity was evaluated by estimating the variance inflation factor. The conventional criterion for absence of multicollinearity (variance inflation factor $<10$ ) was used. A test of model calibration using the Hosmer-Lemeshow test was performed for each model and non-significant $p$-values showed by the Hosmer-Lemeshow test were considered reflective of a well-calibrated model. The significance of all tests was adjusted by the Bonferroni method and a $p$-value $<0.05 / k$ was considered significant to avoid the error of multiple testing, whereas $k$ is the number of the independent variables considered for each univariate or multivariate analysis. SPSS software program (SPSS Inc., Chicago, IL, USA) was used for the database and statistics.

\section{Results}

From 66 water-skiers, 58 water-skiers (49 males and 9 females) were included, and 8 athletes were excluded from the study in according to our exclusion criteria. The median of BMI was 24,163 , with a maximum of 26,794 and a minimum of 19,157 (IQR = 1,674). The median years of practice was 15 , with a maximum of 36 and a minimum of $2(I Q R=5)($ Tab. 1).

One-hundred and sixteen (n.116) upper limbs of 58 athletes were examined. We observed 15 (12.9\%) cases of lateral epicondylitis, 9 in the dominant limbs and 6 in non-dominant limbs, 9 cases in pronated limbs and 6 cases in supinated limbs. Furthermore, we observed 30 (25.9\%) upper limbs affected by medial epicondylitis, 11 cases in dominant limbs and 19 cases in non-dominant ones, of which 8 cases in pronated limbs and 22 cases in supinated ones. Ten (8.6\%) upper limbs were affected by both lateral and medial epicondylitis, 6 in the dominant limbs and 4 in non-dominant limbs, 6 in pronated limbs and 4 in supinated limbs (Tab. 2).

At univariate analysis, taking lateral epicondylitis as the dependent variable, the concomitant diagnosis of medial epicondylitis showed a significant $p$-value $(p<0,007(0,05 / 7))$ (O.R. = 8,100; 95\% C.I. = 2,489$26,355)$. Regarding medial epicondylitis, in addition to 
Table 1

Characteristics of the athletes included in study

\begin{tabular}{|c|c|}
\hline No. of subjects & 58 \\
\hline \multicolumn{2}{|l|}{ Gender, No.(\%) } \\
\hline -Male & $49(84.5 \%)$ \\
\hline -Female & $9(15.5 \%)$ \\
\hline Age in years, median (range (IQR)) & $35(14-60(19))$ \\
\hline $\begin{array}{l}\text { Body mass index, } \mathrm{kg} / \mathrm{m} 2 \text { (median (range } \\
\text { (IQR)) }\end{array}$ & $\begin{array}{l}24,16 \\
(19,16-26,79(1,674))\end{array}$ \\
\hline Years of practice, median (range (IQR)) & $15(2-36(5))$ \\
\hline
\end{tabular}

\section{Table 2}

Characteristics of upper limbs affected by epicondylitis in the population studied

\begin{tabular}{cc} 
No. of examined upper limbs & 116 \\
\hline $\begin{array}{l}\text { Upper limbs affected by lateral } \\
\text { epicondylitis, No.(\%) }\end{array}$ & $\mathbf{1 5}(\mathbf{1 2 , 9 \% )}$ \\
Dominant limbs & $9 / 15$ \\
Non-dominant limbs & $6 / 15$ \\
\hline Pronated & $9 / 15$ \\
Supinated & $6 / 15$ \\
\hline $\begin{array}{l}\text { Upper limbs affected by medial } \\
\text { epicondylitis, No.(\%) }\end{array}$ & $30(\mathbf{2 5}, 9 \%)$ \\
Dominant limbs & $11 / 30$ \\
Non-dominant limbs & $19 / 30$ \\
Pronated & $8 / 30$ \\
Supinated & $22 / 30$
\end{tabular}

\begin{tabular}{cc}
\hline $\begin{array}{l}\text { Upper limbs affected by lateral and } \\
\text { medial epicondylitis, No.(\%) }\end{array}$ & $\mathbf{1 0 ( 8 . 6 \% )}$ \\
& $6 / 10$ \\
Dominant limbs & $4 / 10$ \\
Non-dominant limbs & \\
\hline Pronated & $6 / 10$ \\
Supinated & $4 / 10$
\end{tabular}

the concomitant diagnosis of lateral epicondylitis, also the variable supination of the upper limb during practice demonstrated a significant $p$-value $(p<0,007$ $(0,05 / 7)$ (O.R. = 3,819; 95\% C.I. = 1,529-9,542). No other variables, for both lateral (age, gender, BMI, years of practice, dominance of upper limbs, position of upper limbs during practice) and medial (age, gender, BMI, years of practice, dominance of upper limbs) epicondylitis, showed a significant $p$-value (Tab. 3).

Age and gender adjusted logistic regression between the dependent variable lateral epicondylitis and the independent variable concomitant diagnosis of medial

\section{Table 3}

Significance of indipendent variables for lateral and medial epicondylitis at univariate analysis considering individual upper limbs of the athletes.

\begin{tabular}{l|r|r|}
\multicolumn{1}{c}{} & \multicolumn{2}{c}{$p$-value } \\
\cline { 2 - 3 } \multirow{2}{*}{ Age } & $\begin{array}{c}\text { Lateral } \\
\text { Epicondylitis }\end{array}$ & $\begin{array}{c}\text { Medial } \\
\text { Epicondylitis }\end{array}$ \\
\cline { 2 - 3 } Gender & 0,102 & 0,417 \\
\hline BMI & $0,056^{*}$ & $0,076^{*}$ \\
\hline Years of practice & 0,828 & 0,526 \\
\hline $\begin{array}{l}\text { Concomitant diagnosis of } \\
\text { medial/lateral } \\
\text { epicondylitis }\end{array}$ & 0,088 & 0,074 \\
\hline Dominance of upper limb & & \\
\hline $\begin{array}{l}\text { Position of upper limb } \\
\text { during practice } \\
\text { (Pronated/Supinated) }\end{array}$ & 0,406 & 0,009 \\
\hline
\end{tabular}

${ }^{\circ}$-Significant $p$ value $<0,007$

*-Fisher'Exact Test

epicondylitis, showed a significant $p$-value $(p<0,017$ $(0,05 / 3)$. For the medial epicondylitis, at age and gender adjusted multivariate analysis, both the independent variables concomitant diagnosis of lateral epicondylitis and supinated position of upper limb showed a significant $p$-value $(p<0,0125(0,05 / 4))$ (Tab. 4).

\section{Table 4}

Significance of indipendent variables for lateral and medial epicondylitis at multivariate analysis considering individual upper limbs of the athletes.

\begin{tabular}{|c|c|c|}
\hline \multirow[b]{3}{*}{ Age } & \multicolumn{2}{|c|}{$p$-value } \\
\hline & $\begin{array}{c}\text { Lateral }^{2} \\
\text { Epicondylitis }^{\circ}\end{array}$ & $\begin{array}{c}\text { Medial } \\
\text { Epicondylitis }\end{array}$ \\
\hline & 0,092 & 0,540 \\
\hline Gender & 0,123 & 0,173 \\
\hline BMI & n.i. & n.i. \\
\hline Years of practice & n.i. & n.i. \\
\hline $\begin{array}{l}\text { Concomitant diagnosis of } \\
\text { medial/lateral } \\
\text { epicondylitis }\end{array}$ & 0,002 & 0,001 \\
\hline Dominance of upper limb & n.i. & n.i. \\
\hline $\begin{array}{l}\text { Position of upper limb } \\
\text { during practice } \\
\text { (Pronated/Supinated) }\end{array}$ & n.i. & 0,001 \\
\hline
\end{tabular}

-Significant $p$ value $<0,017$

oo -Significant $p$ value $<0,0125$

n.i. - Not included 


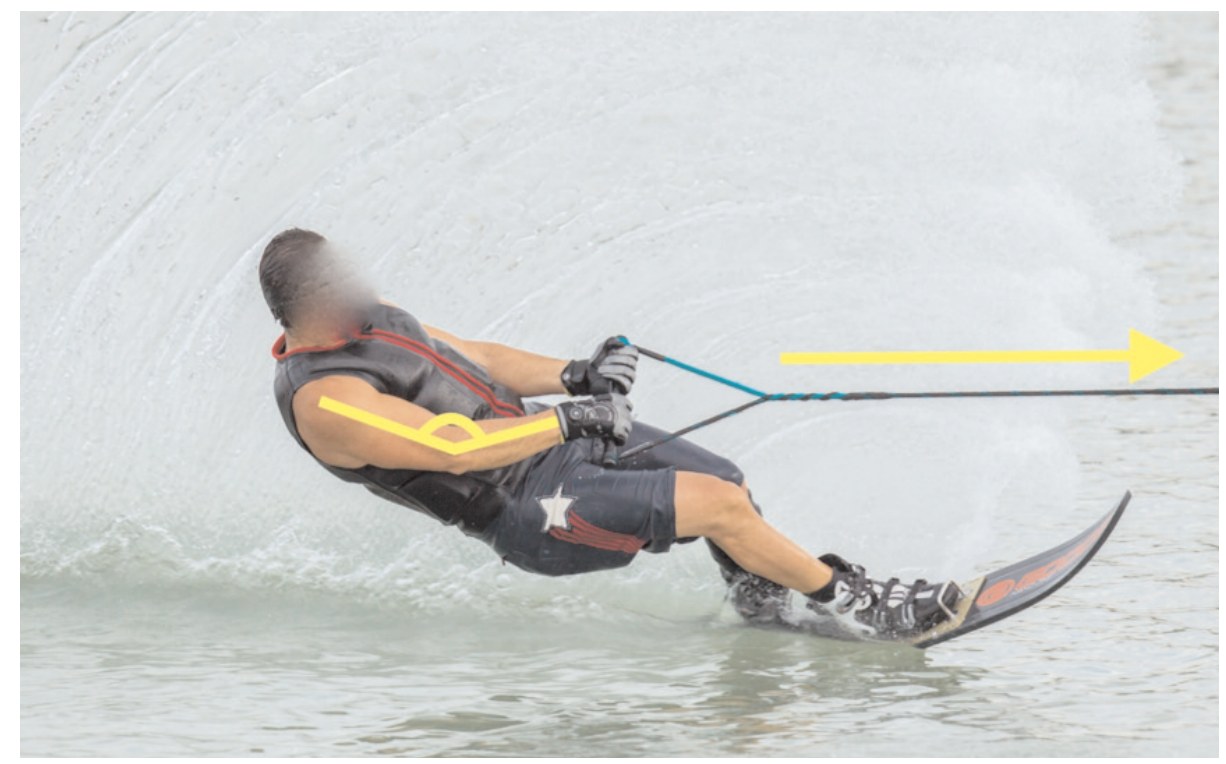

Figure 2. The water-skier position. In this picture it can be observed the traction force pulling water-skiers (yellow arrow) and the flexure of the elbows $<90^{\circ}$ (yellow angle).

\section{Discussion}

The most interesting finding emerging from this study, is a strong statistical correlation between supinated forearm (Fig. 2) and medial epicondylitis. There is not any correlation between pronation and lateral epicondylitis. The present study also demonstrate that subjects affected by lateral epicondylitis were often affected by medial epicondylitis as well, and vice-versa.

For the first time, our study focus on water-skiing related pathologies, in order to investigate intrinsic biomechanical risk factors, such as pronation and supination of forearms, and their correlation with medial and lateral epicondylitis. This suggests the necessity to introduce, as for the well-documented tennis and golfer's elbow, the new concept of "water-skier elbow".

Some limitations of our study must be considered. We carried out a cross-sectional study, with all the limitations implied. The small number of athletes observed, which is partly explained by the scarcity of water-skiers in our region who practice more than 3 hours per week on average, and the scarcity of female (only 9 female athletes of 58 subjects) represent other limitations. Finally, some possible risk factors were not evaluated in our study, such as psychosocial factors, drinking and smoking history.

Clinically, epicondylitis, both lateral and medial, is defined by the presence of pain in the corresponding region of the epicondyle. Most relevant clinical signs are tenderness at the corresponding humeral epicondyle, and pain evoked by the contraction against resistance of the specific epicondylar muscles ${ }^{21}$. Precisely, lateral epicondylitis involves proximal tendons of muscles originating from the lateral epicondyle of the humerus. The muscle most frequently involved is the extensor carpi radialis brevis. Medial epicondyli- tis, which instead involves proximal tendons of muscles originating from the medial epicondyle, most commonly affects the flexor carpi radialis and the pronator teres. In our study, among 116 upper limbs analysed, we detected a high prevalence of lateral $(12.9 \%)$ and medial (25.9\%) epicondylitis, 8.6\% were affected by both lateral and medial epicondylitis. These data support our hypothesis that slalom waterskiing is associated with a higher risk of being affected by epicondylitis. We hypothesise that the high prevalence of epicondylitis (lateral and medial) among pro slalom water-skiers may be partly explained by the traction force pulling the upper limbs of water-skiers.

A possible explanation is the increased epitrochlearis muscles activity during water-skiing practice. Biomechanical studies show that muscles originating from the epicondyle have a central role in limiting elbow dislocation when it undergoes longitudinal forces while staying between 0 and $90^{\circ}$ of flexion ${ }^{22}$. This forced traction may indeed induce stress to the tendons of the epicondylar muscles (Fig. 3).

Mogk and Keir (2003), who analyse the effects of posture on forearm muscles loading during gripping, state that flexor activity was largest in supination. They also concluded that: "Extensor activity was generally larger than that of flexors during low to midrange target force levels, and was always greater when the forearm was pronated. Flexor activation only exceeded the extensor activation at the $70 \%$ and $100 \%$ target force levels in some postures" 23 . Considering water-skiing as a high demanding sport in terms of grip strength, the higher prevalence of medial epicondylitis compared to lateral epicondylitis in waterskiers may be explained. Another hypothesis that can contribute to elucidate the connection between the supinated position and the development of medial epicondylitis, is the radial inclination of the water- 


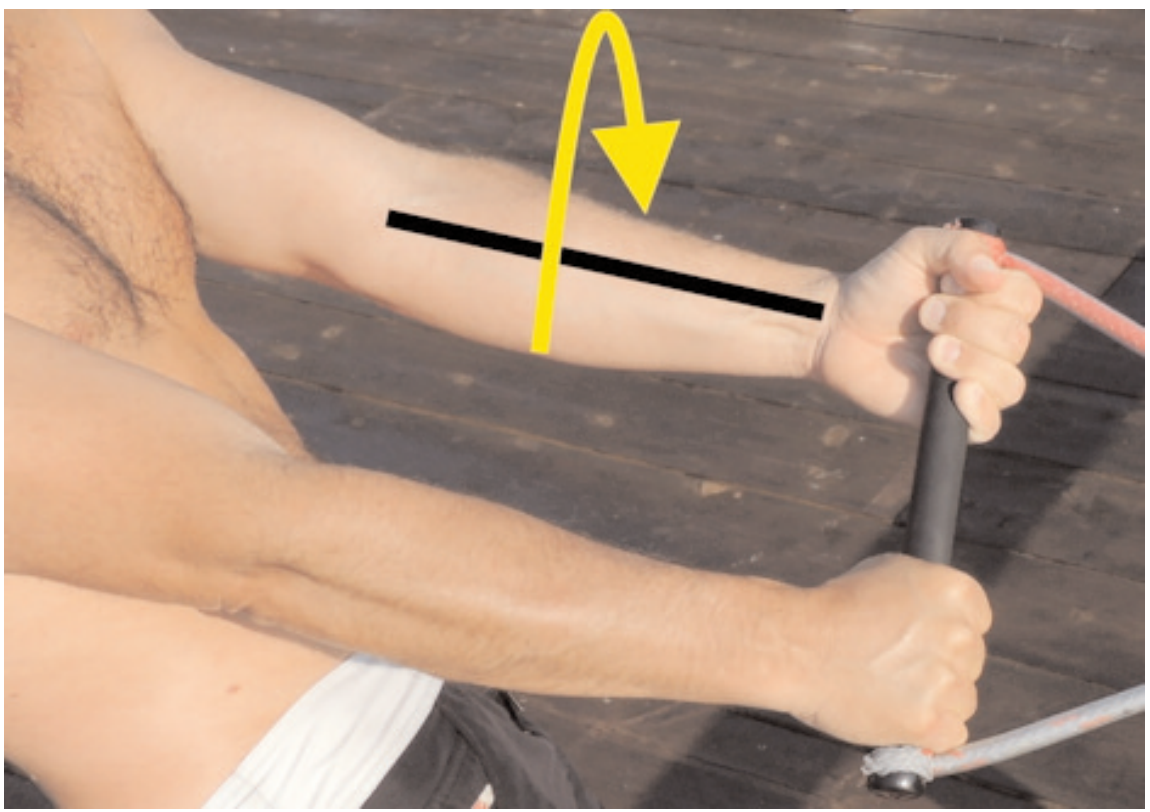

Figure 3. The supination of the forearm during practice. This picture shows the evident supination of the upper limb relative to the hand positioned with the palm up.

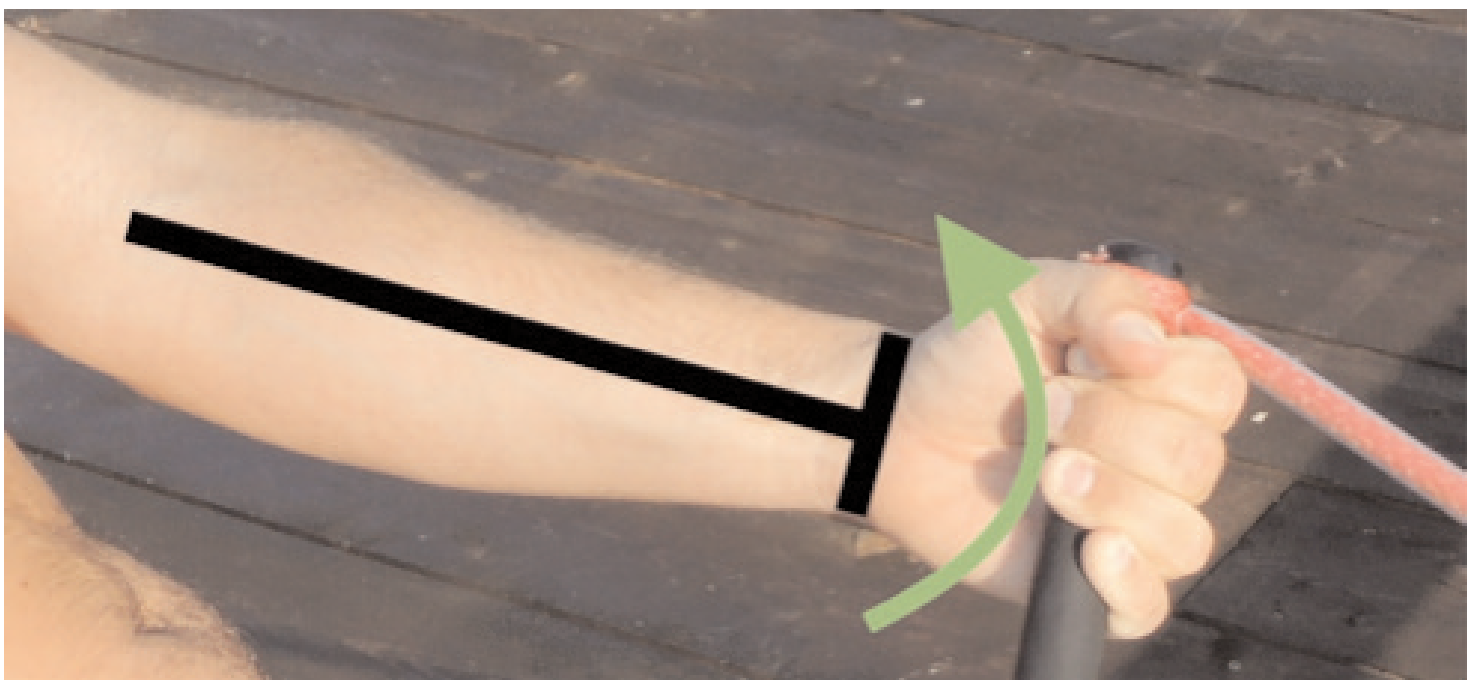

Figure 4. The position of wrist during supination. This picture shows the radial inclination of the wrist relative to the hand positioned with the palm up.

skiers' wrist during practice. Because of the contemporary grip of the pronated hand into the handlebar and its straight conformation, the wrist of the supinated limb is often forced to assume this position (Fig. 4). According to the principles of biomechanics, the position of maximum efficiency of the fingers' flexor muscles is defined as an extension of about $40-45^{\circ}$ and a slight ulnar inclination of about $15^{\circ}$. This position is the most suitable for the hand to perform its function of prehension ${ }^{22}$. Given that muscles originating from the medial epicondylar regions are crucial in this function, the radial inclination of the wrist would also contribute to an excessive expenditure of energy for those. As for lateral epicondylitis, we observed a higher prevalence in pronated forearms, however, the statistical analysis was not significant. The concomi- tant development of medial and lateral epicondylitis is in part explained by the risk factors, already identified in scientific literature, related to both lateral and medial epicondylitis. However, it is very interesting to observe that, in our study, this correlation was observed specifically analysing individual upper limbs. There must be some other reasons which explain why exactly the same limb suffering from medial epicondylitis has a greater chance of being affected by lateral epicondylitis and vice versa. This leads to consider the existence of further factors that influence the onset of lateral and medial epicondylitis in this sport category. Most likely, these factors are closely tied to water-skiing technique itself and/or to other positional and ergonomic factors, which both should be investigated with more specific studies. Despite 
the high prevalence of epicondylitis recorded in these athletes, there is still a substantial lack of studies about water-skiing and their onset. Stemming from this new concept we hope for further studies to explore other possible connections between this discipline and epicondylitis and to deepen the comprehension of the ones pointed out in the present study. Thanks to this comprehension, it would be possible to set several optimal preventive and therapeutic actions. With our study we also want to highlight the importance of positional and ergonomic factors in the pathogenesis of epicondylitis. Subsequently, this new insight would significantly contribute to manage epicondylitis, not only in water-skiers but also in all people involved in prolonged and strenuous activities characterized by forced pronation or supination of the upper limbs or awkward position of the wrist.

\section{Conclusion}

Water-skiing is a very high demand sport for forearms' muscles and tendons. On 116 upper limbs of 58 pro slalom water-skiers examinated, a high prevalence of lateral (12.9\%) and medial (25.9\%) epicondylitis is recorded in our study. Water-skiing can be considered a discipline at high risk for epicondylitis onset, the same way as tennis or golf, defining the new concept of "water-skier elbow". Diagnosis of medial epicondylitis is a positive predictor for the presence of lateral epicondylitis in the same athlete's upper limb, and vice versa. In particular, forced supination during water-skiing practice is statistically correlated with the onset of medial epicondylitis. Further studies are necessary to explore other possible connections between water-skiing and epicondylitis, in order to set several optimal preventive (ergonomic devices) and therapeutic actions.

\section{Conflict of interests}

The Authors declare that they have no conflict of interests regarding the publication of this paper.

\section{References}

1. Khan KM, Cook JL, Maffulli N, Kannus P. Where is the pain coming from in tendinopathy? It may be biochemical, not only structural, in origin. Br J Sports Med. 2000;34:81-83.

2. Khan KM, Cook JL, Taunton JE, Bonar F. Overuse tendinosis, not tendinitis part 1: a new paradigm for a difficult clinical problem. Phys Sportsmed. 2000;28:38-48.

3. Kraushaar BS, Nirschl RP. Tendinosis of the elbow (tennis elbow). Clinical features and findings of histological, immunohistochemical, and electron microscopy studies. J Bone Joint Surg Am. 1999;8:259-278.
4. Rossi J, Vigouroux L, Barla C, Berton E. Potential effects of racket grip size on lateral epicondilalgy risks. Scandinavian Journal of Medicine and Science in Sports. 2014.

5. Hamilton PG. The prevalence of humeral epicondylitis: a survey in general practice. J R Coll Gen Pract. 1986;36:464-465.

6. Shiri R, Varonen H, Heliövaara M, Viikari-Juntura E. Hand dominance in upper extremity musculoskeletal disorders. J Rheumatol. 2007;34:1076-1082.

7. Viikari-Juntura E, Kurppa K, Kuosma E, et al. Prevalence of epicondylitis and elbow pain in the meat-processing industry. Scand J Work Environ Heal. 1991;17:38-45.

8. Shiri R, Viikari-Juntura E. Lateral and medial epicondylitis: Role of occupational factors. Best Pract Res Clin Rheumatol. 2011;25:43-57.

9. Shiri R, Viikari-Juntura E, Varonen H, Heliövaara M. Prevalence and determinants of lateral and medial epicondylitis: A population study. Am J Epidemiol. 2006;164:1065-1074.

10. Martimo KP, Shiri R, Miranda H, Ketola R, Varonen H, ViikariJuntura $\mathrm{E}$. Effectiveness of an ergonomic intervention on the productivity of workers with upper-extremity disorders - A randomized controlled trial. Scand J Work Environ Heal. 2010; 36:25-33.

11. Silverstein B, Welp E, Nelson N, Kalat J. Claims incidence of work-related disorders of the upper extremities: Washington State, 1987 through 1995. Am J Public Health. 1998;88:18271833.

12. Descatha A, Leclerc A, Chastang JF, Roquelaure Y. Media epicondylitis in occupational settings: prevalence, incidence and associated risk factors. J Occup Environ Med. 2003;45: 993-1001.

13. Descatha A, Dale AM, Jaegers L, Herquelot E, Evanoff B. Selfreported physical exposure association with medial and lateral epicondylitis incidence in a large longitudinal study. Occup Environ Med. 2013;70:670-673.

14. Leclerc A, Landre MF, Chastang JF, Niedhammer I, Roquelaure Y. Upper-limb disorders in repetitive work. Scand J Work Environ Heal. 2001:27:268-278.

15. Blackwell JR. Wrist kinematics differ in expert and novice tennis players performing the backhand stroke: Implications for tennis elbow. J Biomech.1994;27:509-516.

16. Schnatz $P$, Steiner $C$. Tennis elbow: a biomechanical and therapeutic approach. J Am Osteopath Assoc. 1993;93:782-788.

17. Farber AJ, Smith JS, Kvitne RS, Mohr KJ, Shin SS. Electromyographic analysis of forearm muscles in professional and amateur golfers. Am J Sports Med. 2009;37:396-401 .

18. Gosheger G, Liem D, Ludwig K, Greshake O, Winkelmann W. Injuries and overuse syndromes in golf. Am J Sport Med. 2003;3:438-443.

19. Bray-Miners J, Runciman RJ, Monteith G. Water skiing biomechanics: a study of advanced skiers. Proc Inst Mech Eng Part P J Sport Eng Technol. 2012;227:137-146

20. Padulo J, Oliva F, Frizziero A, Maffulli N. Muscles, Ligaments and Tendons Journal. Basic principles and recommendations in clinical and field science research. MLTJ. 2013;3(4):250252.

21. Fan ZJ, Silverstein BA, Bao S, et al. Quantitative exposure-response relations between physical workload and prevalence of lateral epicondylitis in a working population. Am J Ind Med. 2009;52:479-490.

22. Kapandji IA. The Physiology of the Joints, Volume 1: Upper Limb, 6th ed. Churchill Livingstone, 2007.

23. Mogk JPM, Keir PJ. The effects of posture on forearm muscle loading during gripping. Ergonomics. 2003;46:956-975. 